\title{
Mediação e Imediatismo': formas sensoriais, ideologias semióticas e a questão do meio
}

Birgit Meyer (Utrecht University)
Quando a pesquisa sobre religião e mídia² tomou impulso há cerca de quinze anos, ambas eram abordadas de início como duas entidades separadas, cada uma com sua própria lógica, e a questão era como uma se relacionava com a outra. $\mathrm{O}$ que, por sua vez, era o reflexo de uma sensação de perplexidade ante a relação inesperada entre religião e mídia. Agora, muitos pesquisadores, inclusive dentro da antropologia, abordam a relação mídia-religião de outra maneira. A mídia é entendida como intrínseca, e não oposta, à religião, e desempenha um papel dentro de amplas práticas religiosas de mediação que conectam os humanos com o divino, espiritual ou transcendental. Essa é uma nova e estimulante perspectiva que nos ajuda a compreender o novo papel da religião em nosso tempo.

Demonstrando que o uso de mídias eletrônicas e digitais tem moldado a transformação da religião (De Vries 2001), trabalhos recentes nesse campo criticam visões rasas da religião como algo que está em perigo de ser corrompido pelas forças dos meios de comunicação em massa, do entretenimento e da lógica de mercado, e afirmam que a adoção da mídia é chave para a manifestação da religião. Com o intuito de transmitir a sensação do que está em jogo, irei apresentar três anedotas etnográficas que mostram diferentes aspectos do uso da mídia em práticas religiosas.

Primeira: No começo de janeiro de 2008, durante uma curta viagem para trabalho de campo em Gana, assisti a um serviço de oração - Jericho Hour organizado pela Action Faith Chapel in Accra. Essa oração ocorre toda quinta-feira, e atrai um grande número de pessoas, sendo que a maioria faz parte de outras igrejas mas sente-se seduzida por esse poderoso evento, no decurso do qual, os pastores prometem "chuvas" de bençãos que se materializariam nos âmbitos da saúde, das finanças, dos vistos e demais tópicos desejados (Meyer 2007) (Figura 1).

Quando as orações começaram, a energia elétrica acabou. A partir disso ficou evidente a importância dos microfones. Tudo ficou em suspenso, e as orações 


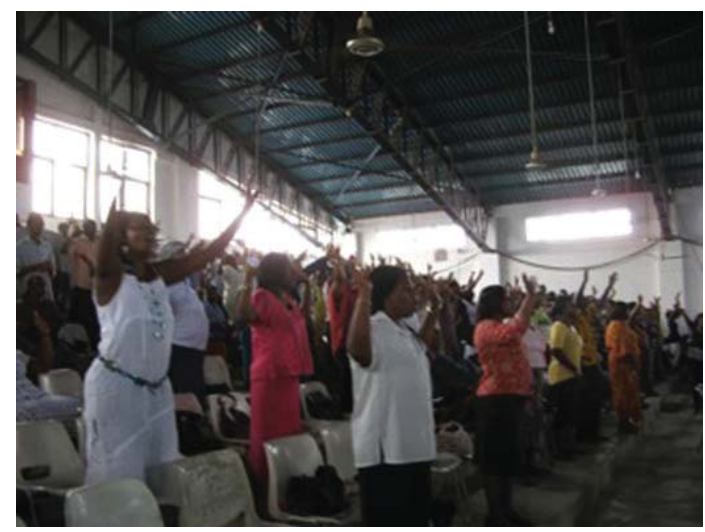

Figura 1: Jericho Hour, Christian Action Faith Chapel, Accra

só puderam continuar quando o gerador foi ativado - indicando a importância do gerador, não apenas para gerar eletricidade, mas como experiência religiosa. A intensidade do som - tamanha que os corpos dos participantes vibravam com seu excesso - e o uso feito pelos pastores do microfone na produção de falas ritmadas induziam uma certa atmosfera de transe que transmitia, por sua vez, a sensação de um encontro extraordinário com uma força divina experienciada como presente, e que poderia ser alcançada com o abrir e estender dos braços.

Dois: em agosto de 2008 eu visitei, junto com Maria José de Abreu, o local de celebração do Padre Marcelo Rossi em São Paulo. O padre é famoso pelo que ele chama de "aeróbica de Jesus", e virou uma celebridade midiática da Igreja Católica com seu próprio programa de TV, CDs de música, filmes e anúncios publicitários. Embora eu já tivesse tido contato com as atividades do Padre no contexto da Renovação Carismática Católica através de Abreu (2005; 2009), a visita à localidade foi verdadeiramente intrigante. Assisti a uma liturgia que seguia mais ou menos a de de uma missa católica. $O$ especial eram as músicas cantadas com entusiasmo pelo padre e sua banda, a qual o povo acompanhava de todo coração, e como isto alterava o ritmo de sua respiração (Figura 2).

Cantar e mexer o corpo fez as pessoas participarem com todos os seus sentidos, não apenas ouvindo. 0 momento mais incrível foi quando Padre Marcelo convidou os participantes a "recarregar suas baterias". Ele pediu a todos nós para esfregarmos nossas mãos de modo a produzir energia, e então tocarmos em nossos vizinhos para experienciar uma sensação de eletricidade, ou choque. A experiência do choque foi mimeticamente reproduzida por ele gritando "brroom brroom", fazendo uso habilidoso do microfone. Isto sugere que tecnologias de amplificação sonora e a metáfora da eletricidade podem bem ser aproveitadas para gerar uma sensação de presença imediata do Espírito Santo entre os presentes.

Três: quando visitei Gana no verão de 2009 para seguir com a minha pesquisa acerca da indústria audiovisual ganense (Meyer 2004), pude perceber a mania dos sakawa. Os garotos-sakawa, dizia-se, buscam ganhar poderes

ganense (Meyer 2004), pude perceber a mania dos sakawa. Os garotos-sakawa, dizia-se, buscam ganhar poderes




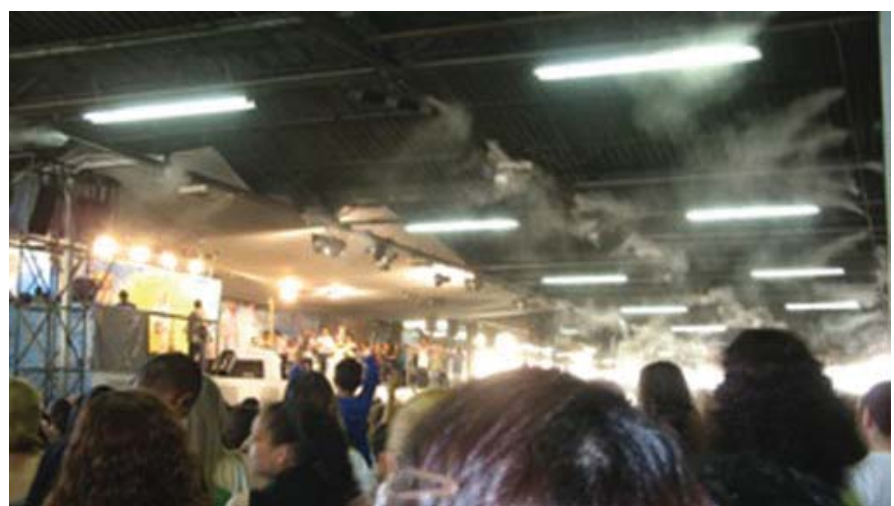

Figura 2: Missa celebrada pelo Padre Marcelo Rossi, São Paulo

espirituais para atrair vítimas inocentes a todo tipo de fraude através da internet (conhecidas como '419'). Enquanto alguns realmente ficam ricos, outros não passam pelo ritual de iniciação - por exemplo, dormir em um caixão por um número de dias - e morrem ou ressurgem mutilados, com uma cabeça de cachorro, por exemplo (veja Figura 3). Uma vez difundidos os rumores sobre estas práticas, que associavam locais de grande desenvolvimento tecnológico e conectividade global, como Lan Houses, com poderes espirituais secretos, uma grande quantidade de cartazes, artigos de jornal e filmes espetaculares que tratavam do fenômeno veio à baila. Eventualmente, a realidade e perigo dos sakawa eram asseverados apontando-se para estes produtos da mídia. Filmes, em particular, eram citados como sendo verdadeiras revelações privilegiadas, dando, assim, credibilidade visual para o que inicialmente começou com rumores vagos: 'É verdade: eu vi naquele filme!'.

Estas anedotas etnográficas de Gana e Brasil apontam para um intrigante conjunto de relações entre mídia novas (ou melhor, recentemente disponíveis) e religião. Enquanto a primeira anedota revela - através da falha tecnológica - a relevância da amplificação sonora para criar um evento de oração poderoso, a segunda invoca uma analogia deliberada entre a tecnologia e aquilo que compõe toda a crença, e a terceira mobiliza o meio cinematográfico para dar credibilidade a algo que começou como rumor acerca de alguns atos espirituais ocultos. Tomadas em conjunto, estas anedotas perfazem um fértil ponto de partida para uma reflexão a respeito do papel e do lugar das novas mídias em práticas de mediação religiosa. Enquanto a mídia, através de suas propriedades tecnológicas, desempenha um papel de protagonismo na criação de tais conexões, ela não se apresenta aos participantes 'como tal'. Essas mídias parecem revestir a mediação de que fazem parte com certo senso de imediatismo, como se o uso de microfones ou filmes rendessem experiências extraordinárias que fariam as pessoas chegar mais perto do divino.

Organizando o volume no qual este texto foi originalmente publicado ${ }^{3}$, Patrick Eisenlohr convidou os autores a endereçar o paradoxo que surge ao situarmos a mídia em um quadro mais amplo de mediação: quanto mais nós 


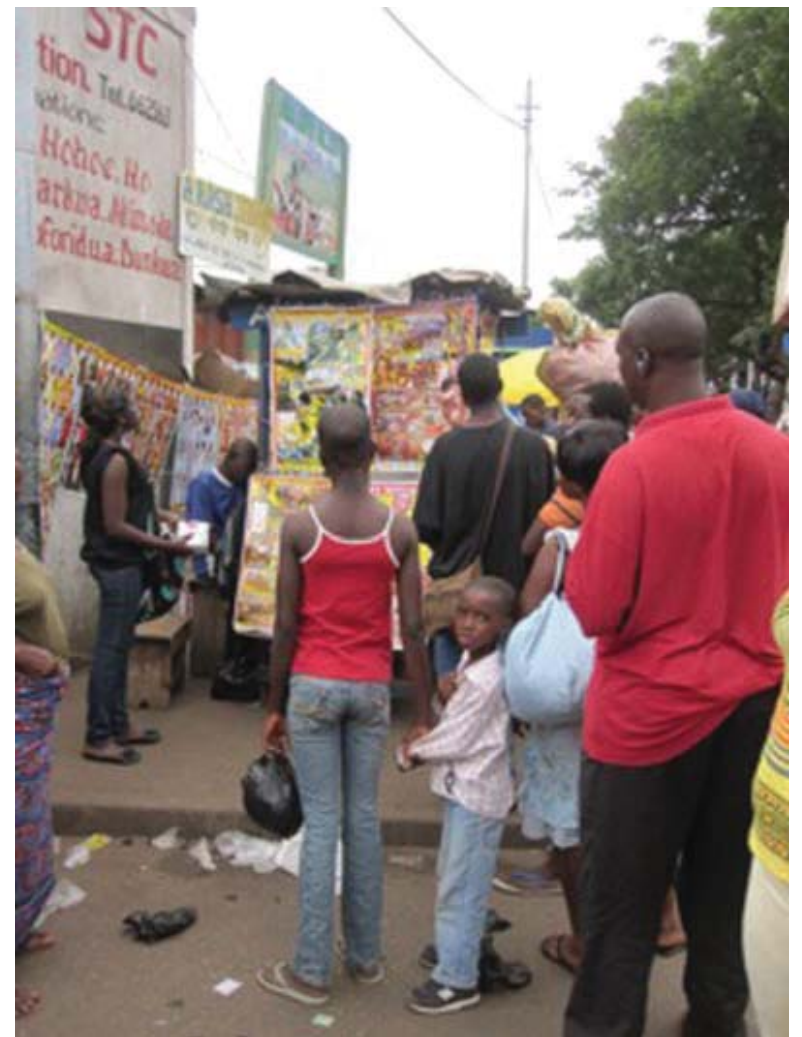

Figura 3: Cartaz publicitando um filme sobre sakawa

reconhecemos a mediação como sendo central para a vida sócio-cultural, menos nós podemos oferecer uma resposta franca para a questão de o que é um meio. A sugestão de Eisenlohr para explorar este paradoxo tomando como ponto de partida 'a propensão da mídia a apagar-se no ato da mediação' (Eisenlohr 2011) é bem colocada.

O ponto aqui não é convocar uma teoria de mídia universalmente válida que dê conta desta propensão ao apagamento ${ }^{4}$, mas propor uma análise dos processos sociais pelos quais a mídia se tornou tão enredada naquilo que contribui para mediar que já não é mais visível enquanto tal, ao menos não para aqueles que estão participando da mediação. Práticas de mediação religiosa parecem particularmente capazes de invocar o senso de presença imediata do divino, como é o caso das primeiras duas anedotas, nas quais o Espírito Santo é invocado, ou então de incorporar o meio cinematográfico de uma forma que ela possa ser aproveitada para produzir uma verdadeira revelação religiosa. Assim, embora pareça, de início, um contra-senso, as anedotas sugerem que a mediação e o imediatismo não pertencem a dois reinos opostos, mas entrelaçados. Esse entrelaçamento é o ângulo pelo qual vou tratar o paradoxo sinalizado por Eisenlohr.

Minhas reflexões são baseadas em, e geradas no interior de um largo programa de pesquisa comparativa, intitulado 'Modern mass media, religion and the imagination of communities', o qual coordenei entre 2000 e $2006^{5}$. Primeiro, vou documentar a já mencionada mudança da oposição dualística para uma noção abrangente de mediação em nosso programa de pesquisa. Argumento que essa mudança requer uma crítica fundamental das abordagens da religião que opõem mídia e imediatismo. Em seguida, com base nesta crítica eu proponho combinar as noções de "forma sensorial" (Meyer 2006a) e "ideologias semióticas" (Keane 2007); estas noções ajudam a conceituar como a realização 
de um senso de imediatismo e presença divina depende de uma prática autorizada de mediação. Em terceiro lugar, argumento que a atribuição de qualidades como "mediado" ou "imediato" a algumas formas e experiências depende de visões específicas e autorizadas segundo as quais as mídias podem "desaparecer", ser presentes e contestadas ou "hiper-aparentes", e relaciono estas modalidades à transformação religiosa. Concluindo, volto-me à pergunta "o que é um meio?" .

\section{DE “RELIGIÃO E MÍdIA" PARA "MEDIAÇÃO"}

Em meados de 1990, após o retorno de Gana a uma constituição democrática e a liberalização e comercialização dos meios de comunicação até então controlados pelo Estado, comecei a me interessar pela relação entre Pentecostalismo e os (então muito populares) vídeo-filmes ganenses (ver, por exemplo, Meyer 2004). Impressionada pelo habilidoso uso feito por pastores convertidos de mídias eletrônicas como cassetes, televisão e rádio que lhes permitiam ser extremamente presentes - tanto visual quanto oralmente - na esfera pública e, reciprocamente, pela apropriação dos modos cristãos de visão e "práticas de visão" pelo cinema popular (Meyer 2006b; ver também Morgan 1998, 2005; Pinney 2004), fiquei intrigada com a relação entre religião e mídia.

Foi isto que me levou a projetar um programa de pesquisa mais amplo. O objetivo era investigar como as religiões se transformam com a adoção de meios de comunicação em massa e, reciprocamente, quanto a cultura (mídia) pública tira partido de repertórios religiosos. Focando nos meios modernos de comunicação em massa, como a televisão, rádio, cassetes e filmes, assim como as TIC (tecnologias de informação e comunicação), o consenso geral do programa de pesquisa era investigar como a (nova) disponibilidade de tais mídias, a partir da liberalização da mídia e da revolução tecnológica, transformou o papel e o lugar da religião na esfera pública.

Inicialmente, nós não pensamos muito sobre a questão do que é um meio. Simplesmente tomamos a resposta como óbvia, pois nosso foco eram os modernos meios de comunicação em massa. No entanto, à medida que nos aprofundamos em nossos respectivos locais de pesquisa, nossa noção de mídia tornou-se mais abrangente, passando a incluir também corpos e coisas. Nosso entendimento moveu-se de uma visão das mídias definidas por tecnologias modernas específicas, em direção a uma visão mais ampla da mídia como meios de transporte de conteúdos que conectam as pessoas umas com as outras e com o divino. A mudança de uma visão tecnológica da mídia para uma social, como ponte entre pessoas e planos acompanhou estimulantes debates sobre a natureza mediada da vida social (Mazzarella 2004) e o potencial da mídia em agir como 'mediador' que molda e afeta o conteúdo que transmite, ao invés de apenas agir como ferramenta de transmissão ou 'intermediário' (Latour 2005:3940). Isso lançou-nos para além da visão estreita e centrada no presente que aborda os meios de comunicação em massa modernos como promotores de algo totalmente novo, fazendo-nos situar a adoção de novas mídias em um quadro histórico de práticas duradouras de mediação religiosa que se transformam, através do tempo, através da negociação de novas tecnologias disponíveis.

Embora seja importante reconhecer que as propriedades das tecnologias de mídia restringem e facilitam certas mediações e modos de comunicação em detrimento de outros, teria sido redutivo fundamentar nossa abordagem 
da mídia em uma visão determinista da tecnologia (ver também Verbeek 2005). De fato, o próprio determinismo tecnológico situa as tecnologias numa visão específica de sociedade na qual estas são instrumentais e, em última análise, desencantadoras. Exemplos como os invocados pelas anedotas, apontando o modo como microfones e filmes estão incorporados às práticas e crenças religiosas, evidenciam como seria irrelevante adotar uma visão da mídia como tecnologias neutras que agem de acordo com uma lógica própria ${ }^{6}$. O ponto é que a tecnologia nunca 'vem em uma forma "puramente" instrumental ou material - como pura possibilidade tecnológica a serviço do imaginário religioso' (Van de Port, 2006:455), mas é incorporada a este último através de um processo de negociação frequentemente complicado no qual estruturas de autoridade estabelecidas podem ser contestadas e transformadas (ver também Eisenlohr 2006; Kirsch 2008; Larkin 2008; Schulz 2003, 2006).

A conceitualização da religião como mediação foi um grande passo em nosso programa de pesquisa, porque nos alertou para um preconceito implícito e escassamente reconhecido contra a mídia no estudo da religião (veja também Meyer e Moors 2006). Como já mencionado, o interesse acadêmico na relação entre religião e mídia foi gerado por uma perplexidade inicial ante a interação entre esses campos que eram imaginados não só como separados, mas também como pertencendo a registros completamente diferentes. Eu gostaria de argumentar que essa complexidade remete a visões protestantes de religião, ecoadas por acadêmicos como Max Weber (1970 [1948]) e William James (1982 [1902]), que colocam a experiência pessoal e encontros imediatos com o divino como núcleo e consideram forma e estrutura (da igreja) como secundários. Significado, conteúdo e crença interior são privilegiados em prejuízo dos meios, formas e atitudes exteriores. Tal visão reflete autodescrições do Protestantismo como desenvolvido em reação à ênfase Católica nos sacramentos e no uso de imagens. A carga protestante de iconoclastia pode ser proficuamente analisada como choque entre visões concorrentes sobre mediação. Significativamente, a crítica protestante do poder atribuído aos meios na igreja católica e sua própria ênfase na leitura da bíblia não produziram simplesmente um apelo à substituição de um meio (ícone) por outro (texto bíblico). O que se encontrava em jogo era um deslocamento para fora da mediação, rumo ao imediatismo. A visão protestante descartava a mediação religiosa como feita por humanos e, portanto, equivocada na aproximação a Deus. Apenas na leitura da bíblia - a palavra viva de Deus - os crentes poderiam atingir uma conexão pessoal e imediata com Deus sem a interferência de autoridades religiosas.

Isto é, por si só, uma intrigante teoria da mediação que não deveria, entretanto, ser tomada à letra por acadêmicos. A tensão entre a ênfase protestante em um encontro imediato entre os crentes e um Deus que se acredita ser avesso a representações humanas, por um lado, e a dependência factual de algum tipo de mediação para poder entrar em contato com Ele foi capturada por Matthew Engelke (2007) como o 'problema da presença'. Este problema da presença surge da negação concomitante da mediação $e$ o esforço no sentido de encontros imediatos com Deus que demandam algum tipo de mediação. Essa posição contraditória é acoplada a desconfianças protestantes em relação à 'mera' forma, e sua busca pelo conteúdo 'real' localizado além desta (Meyer 2012a).

Como já estabelecido, a suspeição ante a mídia não é exclusiva ao protestantismo, mas também moldou o estudo (antigo) da religião como uma disciplina moderna. Tomando o texto bíblico como um meio que distorce 
o conteúdo original, o 'pai' dos estudos religiosos, Max Müller (1893; veja também Fox 2009: 4-9), por exemplo, apontou a necessidade de formas adequadas para interpretação que levam de volta à origem imediata daquilo que foi armazenado imperfeitamente em forma textual ('palavra' se tornando 'carne' de novo, a preocupação da 'hermenêutica bíblica'). Aqui imediatismo é tipicamente entendido - e privilegiado - como sendo anterior à mediação.

Richard Fox (2009) argumentou que esta visão ecoa ainda em muitas teorias contemporâneas de mídia que fazem distinções entre forma e conteúdo, ou meio e mensagem, e privilegiam este último em detrimento da primeira por ser mais genuíno. Concordo com Fox que, certamente, no entendimento do senso comum, a mídia ainda é entendida costumeiramente como meio para compensar a falta - ou mesmo a perda - do imediatismo. Nesta perspectiva, as mídias são defeituosas, pois conseguem transmitir apenas uma experiência mediada, de segunda mão. Em contraste, uma das preocupações teóricas centrais em pesquisas recentes sobre religião e mídia é criticar e transcender essa perspectiva problemática, segundo a qual a mídia - entendida como ferramentas instrumentais ou veículos de conteúdo - compromete e aliena por definição ${ }^{7}$. Sob a perspectiva da mediação que já informou grande quantidade de trabalhos recentes sobre a ligação religião-mídia, a mídia é entendida como participante na efetivação do divino ou transcendental. Ela produz crença (ver também De Certeau 1984; Derrida 2001).

\section{FORMAS SENSORIAIS E IDEOLOGIAS SEMIÓTICAS}

A fim de entender como o divino ou transcendental são efetivados pela mediação, cunhei a noção de "forma sensorial" (Meyer 2006a). Formas sensoriais são modos relativamente fixos para invocar e organizar o acesso ao transcendental, oferecendo estruturas de repetição que criam e sustentam conexões entre crentes no contexto de regimes religiosos específicos. Essas formas são transmitidas e partilhadas; elas envolvem praticantes religiosos em práticas específicas de adoração, e desempenham papel central na modulação destes em sujeitos e comunidades morais religiosos. Apelando a uma reconsideração da importância da "forma" como sendo uma condição necessária sem a qual o "conteúdo" não pode ser transportado, sustento que, para mim, "forma" não é oposta a "conteúdo", "significado", ou "substância". Esta oposição reproduz um problemático entendimento protestante de religião que descarta a forma como uma questão externa, privilegiando em vez disto conteúdo e crença 'interna' (Meyer 2010a; ver também Asad 1993).

Como argumentado na seção anterior, é urgente reconhecer que esse entendimento consagra uma teoria de mídia religiosa particular e historicamente situada que certamente demanda análise, mas não deveria constituir ponto de partida incontroverso na pesquisa sobre a relação religião-mídia. Incluindo todas as mídias - amplamente entendidas como mediadores - utilizadas na conexão com a esfera do transcendental, a noção de forma sensorial é destinada a explorar como a mediação transmite um senso dessa esfera.

É necessário ressaltar que a noção de forma sensorial não pressupõe a primazia dos sentidos como arautos da experiência religiosa, mas aponta para a necessidade de enfocarmos formas autorizadas que organizam tal experiência. Encontra-se aqui uma diferença significativa em relação aos métodos (desenvolvidos por exemplo, no âmbito da antropologia dos sentidos) que postulam uma fenda entre os registros da linguagem e do simbólico, 
por um lado, e o da experiência, por outro, e de acordo com as quais este último é mais direto e genuíno que o primeiro. A meu ver, abordar o paradoxo da mediação e imediatismo requer o desenvolvimento de uma nova síntese entre abordagens que ressaltem a importância dos sentidos e da experiência e abordagens que ressaltem as formas e os códigos que são a base dos sistemas culturais e religiosos.

No presente caso, a noção criada por Webb Keane de 'ideologia semiótica' é de particular interesse. Se a ideia de formas sensoriais aponta para a organização da experiência religiosa, a de 'ideologia semiótica' nos ajuda a obter um entendimento mais claro do status que está sendo atribuído a palavras, coisas ou imagens, a partir da perspectiva de uma tradição religiosa específica e historicamente situada. Ele desenvolveu essa concepção em seu estudo dos encontros entre missionários protestantes alemães e os Sumba na Indonésia de modo a compreender melhora as diferentes formas pelas quais ambos os lados interpretavam o poder e o valor de, por exemplo, palavras e coisas. Keane baseia essa noção no conceito de 'ideologia da linguagem', isto é, 'aquilo que se acredita sobre linguagem' (2007: 16) ou, nas palavras de Michael Silverstein, 'conjuntos de crenças sobre linguagem articulados pelos usuários como a racionalização ou justificação do uso e da estrutura da linguagem percebidos' (citado em Keane 2007:16). Ideologia é usado aqui não no sentido de uma falsa consciência, mas para ressaltar 'os efeitos produtivos da consciência reflexiva' (Keane 2007: 17), o ponto sendo que essas ideologias não são confinadas no nível da representação imaterial, mas sempre requerem objetificação no mundo material. Ideologias linguísticas, entendidas neste sentido, figuram em ambiências materiais concretas que são habitadas por pessoas. Ao invocar a ideologia 'semiótica' ao invés da 'linguística', Keane busca abranger outros domínios semióticos além da linguagem apenas. Especialmente importante neste caso é a distinção de Peirce entre ícone, índice e símbolo, que oferece uma teoria mais complexa da relação entre signos e o mundo que a linguística de Saussure, que pressupõe uma divisão entre representação e realidade. Ideologias semióticas identificam, portanto, categorias significantes de signos e definem suas relações com a realidade de maneiras particulares que organizam o mundo material.

A utilidade da noção de ideologia semiótica no tocante à exploração da atribuição de valor e poder a modos de fala e expressão em práticas de mediação religiosa é óbvia. Em sua já mencionada pesquisa inovadora sobre os Friday Masowe Apostles (Engelke 2004, 2007), que consideram a Bíblia como uma coisa que distrai e interfere no caminho do contato 'real' com Deus e pode, por conseguinte, ser usada como papel higiênico, Matthew Engelke revela uma ideologia semiótica ultra-iconoclasta que considera coisas como problemáticas por causa de sua 'coisidade' ao mesmo tempo em que acata o uso de substâncias como mel. Embora, segundo uma perspectiva externa ao grupo, uma tal substância possa ser identificada como 'coisa', o ponto crucial é que, segundo uma perspectiva interna, o mel é codificado como algo para além da materialidade.

Este é um exemplo particularmente intrigante, porque mostra como o descarte de coisas não exclui recorrência àquilo que identificaríamos como matéria - o ponto sendo que aquilo que é qualificado como matéria desde fora pode bem ser enquadrado como "espiritual" no âmbito de uma ideologia semiótica específica. Embora a Bíblia seja para os Friday Masowe Apostolics imprópria para conectá-los com Deus, eles consideram mel como arauto viável do espírito de Deus. 
A consecução de um senso de imediatismo que caminha lado a lado com a qualificação do mel como "espiritual", e portanto como meio que torna-se uno com a substância que transmite, depende obviamente de enquadrar o mel com base em uma ideologia semiótica específica e colocá-la como forma sensorial específica. Num outro caso intrigante de uma Igreja Pentecostal Africana na Zâmbia, Thomas Kirsch (2008) mostrou que o uso do texto bíblico e liturgias escritas não precisam ficar no caminho de, mas sim preparar para um encontro imediato com o Espírito Santo, contestando portanto a oposição costumeira entre oral e escrito, e Espírito e Letra, que informa ainda muitos acadêmicos.

Esses casos etnográficos sugerem que o que um meio é e faz não é intrínseco ao próprio meio, e sim resultado de processos sociais que moldam a mediação religiosa e autorizam algumas formas sensoriais como válidas. Como Patrick Eisenlohr (2006) também argumentou, com relação a seu trabalho sobre a autorização de fitas cassetes religiosas entre Muçulmanos nas Ilhas Maurício, o reconhecimento da capacidade das novas tecnologias para mediação, e mesmo a transmissão de imediatismo, não depende das próprias tecnologias, estando, em vez disso, enraizado em noções e práticas mais amplas que atribuem certas capacidades a essas tecnologias.

Neste sentido, não existe distância radical entre substâncias como mel, a Bíblia ou os meios de comunicação em massa modernos, como eles todos podem ser aproveitados como meios que operam com formas sensoriais autorizadas. Sintetizar as noções de formas sensoriais e ideologia semiótica cria pontes entre duas abordagens epistemológicas tomadas até então como distintas, mas que necessitam ainda ser conjugadas para que possamos entender como e por que códigos semióticos são tidos como fundamentos de certas tradições religiosas ou perspectivas de mundo. Em outras palavras, essa síntese permite-nos compreender como formas semióticas se tornaram persuasivas e são experienciadas, em último caso, como reais e imediatas (veja também Van de Port, 2009).

\section{MODALIDADES DE MÍDIA E A TRANSFORMAÇÃO DA RELIGIÃO}

Uma das questões em torno das quais se desenvolveu minha reflexão sobre os achados de nosso programa de pesquisa foi como novas (ou recentemente disponíveis) mídias impactam formas sensoriais estabelecidas e relacionam-se com ideologias semióticas características a regimes religiosos específicos ${ }^{8}$. O problema da adequação de antigas e novas mídias para mediar poder espiritual talvez dê origem a veementes discordâncias e contestações, mas também faz com que a mídia "desapareça" ou se torne aquilo que eu chamaria de "hiper-aparente".

\section{‘DESAPARECIMENTO’ DA MÍDIA}

Em muitas das configurações de pesquisa que nós encontramos, notamos que nas práticas de mediação estabelecidas não havia nenhuma separação clara entre meio e mensagem, ou forma e conteúdo, no nível dos praticantes religiosos. Por exemplo, para os Ewe, uma estátua legba não é entendida como constituindo um mero objeto material que tem um espírito por trás, mas como uma real corporificação de poder espiritual (Meyer 2010b), bem como, no catolicismo, ícones transmitem uma sensação de Deus (a rejeição a "ídolos" feitos por humanos, 
apontando a pura materialidade do ícone, é uma crítica típica dos Protestantes para com a mediação Católica). De maneira similar, apesar da questão sobre o uso do rádio para leituras públicas do Corão ser ou não adequado ter envolvido negociações complicadas entre Muçulmanos no norte da Nigéria no período colonial (Larkin, 2009; veja também abaixo), uma vez tomada a decisão a favor, tais leituras formaram uma parte praticamente natural da vida pública na qual o Islã é onipresente. Todos estes exemplos, e as anedotas etnográficas apresentadas na introdução, mostram que aquilo que pode ser identificado como 'mídia' a partir da perspectiva analítica de quem está de fora (como nós) pode ser percebido como sendo totalmente incorporado à prática religiosa.

Isso nos leva ao cerne do problema do 'desaparecimento' do meio. As mídias que estão envolvidas na invocação e no entrar em contato com certos poderes divinos e em vincular e ligar crentes, é feita para 'desaparecer' através de formas sensoriais religiosas estabilizadas e autorizadas que marcam tais mídias como genuínas à substância mediada por elas. Desta forma, as mídias são autenticada como parte inextricável do próprio transcendental que é alvo de -e, a partir de uma perspectiva de fora: invocada pela - mediação. Em outras palavras, a mediação em si é sacralizada (ver também Chidester 2008) e provida de um senso de imediatismo pelo qual a distância entre os crentes e o transcendental é transcendida através de formas sensoriais e ideologias semióticas específicas (ver também Van de Port, 2009).

Assim, a mídia tende a "desaparecer" quando é aceita como dispositivo que, naturalmente, por assim dizer, "desaparece" na substância mediada por ela. Esse "desaparecimento" fenomenológico deriva do fato de que o meio e a mensagem, forma e substância, não são separados analiticamente. Reciprocamente, as mídias 'aparecem' se a síntese é quebrada. Este é com frequência o caso quando se contesta se determinado meio é apropriado para a transmissão de um conteúdo especifico (e, claro, também em análises acadêmicas). O ponto aqui é que "aparecimento" e "desaparecimento" da mídia é socialmente produzido e depende de perspectivas autorizadas do que a mídia é e faz, ou não deve fazer, em formas mais amplas de mediação.

\section{MÍDIA CONTESTADA}

As mídias são mais explicitamente marcadas e sujeitas ao debate quando a (in)adequação de um meio específico é questionada ou quando novas mídias se tornam disponíveis e surge a questão de se estas deveriam ser incorporadas, e como ${ }^{9}$. Em contraste, como argumentado no parágrafo acima, uma vez que são inteiramente incorporadas em práticas de mediação, é improvável que sejam reconhecidas explicitamente e tendem, portanto, ao "desaparecimento". Eu já invoquei a iconoclastia Protestante como contestação de mídias existentes e práticas Católicas de uso da mídia, gerando novas formas sensoriais (leitura bíblica) e ideologias semióticas (desvalorizando ícones, supervalorizando o texto). Também no mundo contemporâneo, grupos religiosos se esforçam para lidar com a onipresença dos meios de comunicação em massa. Até muito depois da televisão se tornar disponível, Protestantes ortodoxos na Holanda descartaram esta tecnologia e esperaram que seus membros não assistissem. Em contraste, agora existem canais especiais destinados a esse público, mostrando que a Cristandade evangélica e espetáculos cristãos televisionados, como concertos pop, podem agir em conjunto (Van der Stoep 2009). 
Em Gana, desde a liberalização e comercialização da imprensa escrita, filme, rádio e televisão, o movimento neo-tradicional Afrikania luta para resgatar a 'Religião Tradicional Africana' dos ataques das igrejas Pentecostais que se tornaram hegemônicas no sul de Gana. Comparando as práticas midíaticas do movimento Afrikania e da denominação Pentecostal-Carismática Internacional Central Gospe/ Church (ICGC), Marleen de Witte (2008) mostra que Afrikania encontra dificuldade em se acomodar à predominância da visibilidade que prevalece na esfera pública corrente de Gana. Enquanto Afrikania busca dominar sua própria representação nos meios de comunicação em massa, paradoxalmente, os sacerdotes tradicionais que ela diz representar desejam manter uma aura de segredo, insistindo que os deuses e suas moradas não se prestam à captura pelas lentes da câmera e à reprodução na tela, pois isso irá acarretar em perda de poder espiritual.

Outro intrigante caso relacionado compõe o estudo de Mattijs Van de Port (2009) sobre como o Candomblé, apesar de se ter tornado uma presença significativa na esfera pública da Bahia, consegue engajar-se na 'performance pública de sigilo', afirmando que as mídias visuais modernas, tais como a televisão e o cinema, não são capazes de capturar o que realmente é o Candomblé. Brian Larkin (2009) mostrou como a disponibilidade da imprensa e do rádio, codificados como mídias primárias da modernidade colonial, tornou-se capital para conflitos sobre as modalidades através das quais supunha-se que o Islã deveria estar presente em público. Ele argumenta que a adoção destas mídias modernas pelo Sheik Abubaker Gumi foi parte da reformulação do Islã, um projeto através do qual este foi alinhado a uma prática religiosa mais racional que se encaixa no Estado moderno e secular.

O ponto é que a disponibilidade de novas mídias pode causar deliberações críticas sobre seu potencial para gerar e sustentar experiências espirituais genuínas e formas de autoridade dentro de tradições religiosas existentes. Como mensagem e meio, conteúdo e forma, existem apenas em conjunto, a pergunta central é como mediações anteriores são transformadas por serem re-mediadas através de novas mídias (Bolter e Grusin 1999; Meyer 2005; Hughes 2009; Oosterbaan 2009), e se - e como - tais re-mediações são autenticadas como arautos aceitáveis e adequados da experiência religiosa, modos de comunicação e maneiras de expressão da presença pública ${ }^{10}$. Debates e conflitos sobre mídia e as novas formas de presença pública que elas permitem são centrais para transformações religiosas e, portanto, um ponto de partida fértil para estudar dinâmicas religiosas.

\section{MÍDIA 'HIPER APARENTE'}

Apesar dos exemplos que acabamos de dar apontarem para hesitações em relação à adoção de novas mídias de massa, são frequentes as situações em que novas mídias audiovisuais estão sendo avidamente incorporadas nas práticas de mediação religiosa, gerando novas formas sensoriais. Maria José de Abreu (2009) mostra que para a Renovação Carismática Católica (RCC), a televisão é considerada uma tecnologia moderna adequada para tornar presente o Espírito Santo. Analisando as ricas experiências somáticas dos carismáticos no contato com o Espírito, ela divisa uma reveladora homologia entre o Espírito Santo e um "gerador de eletricidade" que "infunde energias", e a associação dos corpos dos crentes a "antenas de retransmissão". Aqui, a televisão não é considerada como um corpo estrangeiro, mas como excepcionalmente útil à filtragem da mensagem da RCC para o público. O meio 
torna-se portanto hiper-aparente, no sentido de que é celebrado como uma realização tecnológica de modos religiosos já existentes de olhar e visualizar. O meio é sacralizado como cumprimento de um projeto religioso que transcende a mediação e produz imediatismo.

Uma ideia parecida de transmissão direta subjaz à análise de Rafael Sánchez (2009) dos Pentecostais participantes de uma ocupação em Caracas, que encaram seus próprios corpos capturados pelo Espírito Santo como seu principal meio e, por sua vez, tomam posse de quaisquer casas ou bens que o Espírito os autoriza. Sánchez analisa os cultos Pentecostais na Monarchical Church, em Caracas como um "contexto televisual" no qual participantes erguem seus braços, como uma "floresta de antenas", ávidos por transmitir "ao vivo" o poder do Espírito Santo. Esses exemplos sugerem notáveis afinidades eletivas entre modos religiosos de representação e novas tecnologias audiovisuais (veja também Pinney 2004; Stolow 2010).

O que se encontra em jogo é, em outras palavras, a confluência de novas tecnologias de mídia e o espírito que elas dizem tornar acessível. Nesse sentido, o poder espiritual é materializado no meio e predicado para tocar as pessoas de maneira imediata. Ao invés de desaparecer na mediação, a mídia aqui se torna hiper-aparente. Como Bolter e Grusin (1999) mostraram, frequentemente a introdução de novas mídias, como, por exemplo, os celulares, realça a capacidade que o novo meio tem de habilitar a comunicação imediata (ver também Van de Port, 2009). Tanto a mídia "em desaparecimento" quanto a "hiper-aparente" sugerem completa consonância entre o meio e o que ele transmite, borrando portanto a noção de "forma" e "substância". Nesse sentido, o meio "hiper-aparente" atinge uma aparência diferente daquela de quando nos referimos à mídia em termos de tecnologias específicas.

\section{AFINIDADES ELETIVAS ENTRE TIC E O ESPÍRITO SANTO: CONEXÕES IMEDIATAS}

Até agora eu olhei para maneiras pelas quais novas mídias são negociadas e possivelmente incorporadas a práticas religiosas de mediação. Entretanto, a negociação da mídia por grupos religiosos não ocorre em um vácuo. Em muitas configurações, a ganense inclusive, a liberalização e comercialização da mídia sinalizou uma mudança significativa com relação à capacidade do Estado de monopolizar e controlar o acesso aos meios de comunicação em massa, como filmes, rádio, televisão e imprensa escrita. Essa mudança ocorreu dentro de um processo mais amplo de democratização e neoliberalização, pelo qual o Estado recuou do controle direto do domínio público e do mercado. Como a 'disponibilidade' da mídia depende de políticas, o acesso e uso da mídia é político.

De forma relevante, em tais configurações as mídia não se encontram simplesmente disponíveis como tecnologias neutras, transmitindo em vez disso visões particulares do mundo. Ao mesmo tempo que a anedota etnográfica sobre os sakawa presente na introdução desse artigo aponta para ansiedades e desejos desencadeados pela possibilidade de interagir com pessoas distantes através da internet, fica também claro que as novas tecnologias de informação e a visão de mundo por elas transmitida têm forte apelo em Gana. Durante recentes permanências em campo, percebi que as propagandas de telefones celulares e companhias de TIC revelam uma preocupação com a mobilidade espacial e social, conectividade e imediatismo (ver Figura 4). Conexões globais e contato imediato é o que estas tecnologias prometem trazer. Em outras palavras, elas invocam uma visão particular do global. Ele 


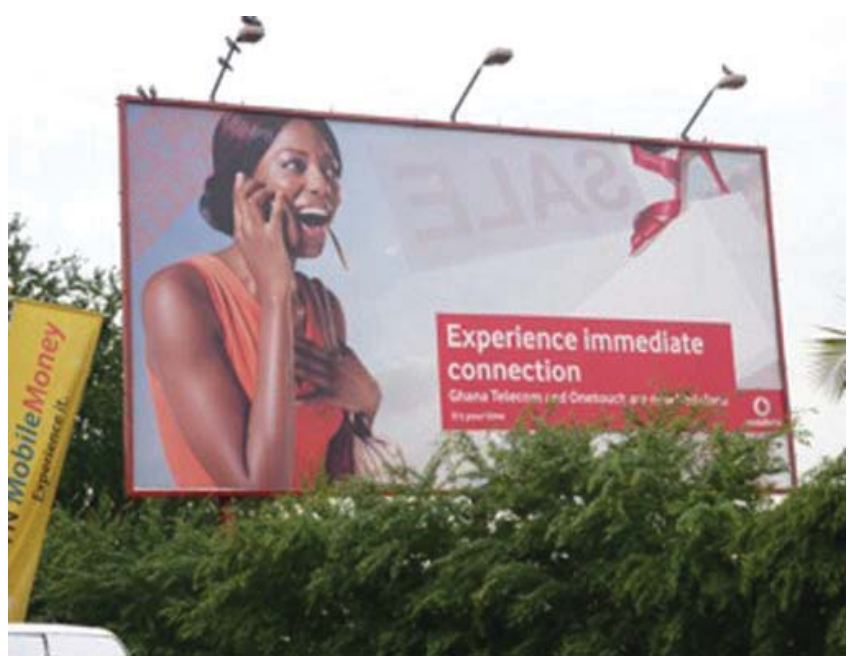

Figura 4: Experimente correção imediata: publicidade de Vodaphone, Accra

não está em algum lugar "lá em cima" e longe, sua realização é prometida em conexões imediatas entre pessoas reais que tenham as tecnologias apropriadas. Estar posicionado na rede certa implica não apenas comunicação instantânea, mas também ter domínio sobre o mundo, como sugere o recente anúncio feito para a nova rede Glo, usando rostos de artistas conhecidos e prometendo enfaticamente: governe seu mundo. (Ver Figura 5). Essas tecnologias estão situadas em infraestruturas tecnológicas globais que estão parcialmente sob controle dos estados, mas que também escapam dele, ao prometer um certo nível de domínio aos usuários.

A meu ver, esta visão de uma conectividade global através das novas tecnologias que permitem encontros "diretos" e "ao vivo" tem uma afinidade eletiva com o projeto Pentecostal de conectar os crentes em redes globais de convertidos e sua ampla visão do mundo como conectado através de circuitos tecno-religiosos alimentados pelo Espírito Santo. A ideia de "governar" seu próprio mundo e a visão Pentecostal da espiritualidade como individual e separada de espíritos que corporificam laços sociais tradicionais - com famílias extensas ou aldeias (Meyer 1998) - claramente ressoam uma na outra. Em Gana, ao menos, Pentecostais têm se mostrado muito bem sucedidos em se apropriar das novas tecnologias midiáticas disponíveis e incorporá-las em formas sensoriais particulares que produzem encontros imediatos com o Espírito Santo, pelo qual os crentes convertidos serão preenchidos.

A impressionante similaridade entre interpretações Pentecostais do Espírito Santo, por exemplo, em termos de eletricidade, e a visão global de conexões imediatas propostas por anúncios de TIC mostra mais uma vez as insuficiências de uma definição meramente tecnológica de mídia. Os anúncios das TIC jogam luz sobre o 


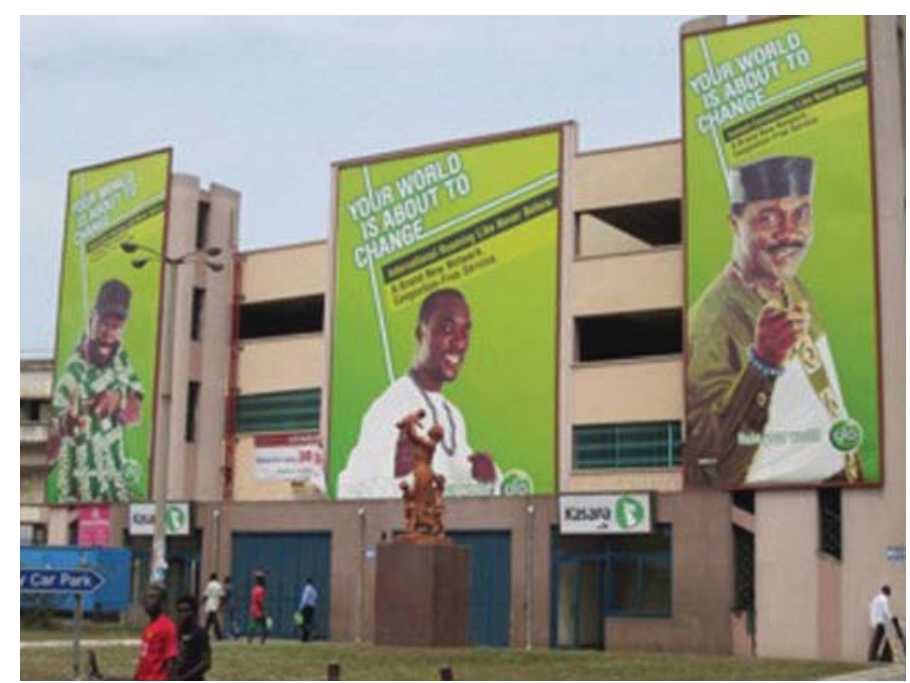

Figura 5: Controla teu mundo: publicidade de Glo, Accra

fato de que estas mídias encontra-se elas próprias incorporadas a mediações particulares que conectam o local e o global. Ao analisar essas afinidades eletivas, não visamos reduzir os projetos religiosos e visões de mundo a meras tecnologias, mas explorar em que extensão a lógica do alcance da religião e a sedução e visão de mundo que acompanham as tecnologias midiáticas confirmam-se reciprocamente. A mídia oferece novas possibilidades para transformação religiosa.

\section{CONCLUSÃO: "O QUE É UM MEIO?"}

Há um tempo, dei o manuscrito de um artigo em andamento a um dos meus estudantes de mestrado em antropologia, um jovem ganês de origem Pentecostal. Alinhado ao argumento desenvolvido acima, naquele artigo procurei mostrar que o uso específico da mídia em cultos Pentecostais é sancionado por formas sensoriais específicas, através das quais as mídias são sacralizadas, tornando-se, portanto, propensas a "desaparecer" ou se tornar "hiper-aparentes", transmitindo por isto uma sensação de encontro imediato com Deus. Ele comentou:

Na página 14 você escreveu: “Isso não é dizer que a mídia é chamada apenas para criar - para não dizer falsear - a presença do Espírito Santo, mas para indicar o entrelace inseparável da mídia na comunicação religiosa"... Honestamente, as descrições anteriores realmente fazem parecer que é isso que você está dizendo. Talvez você deva reformular.

Eu não segui sua sugestão de "reformular". Embora eu tenha tentado entender as dinâmicas pelas quais a mídia é incorporada na mediação do Espírito Santo de tal maneira que ela praticamente "desaparece", isso não 
significa que essas mídias não estejam mais lá. “Desaparecimento” é alcançado através de certos atos e perspectivas compartilhadas. Buscando explicar a incorporação das mídias em uma forma sensorial religiosa particular, de modo a entender como, ao serem sacralizadas, transmitem um senso de imediatismo, penso a mídia em dois níveis. Aqueles que participam de uma forma sensorial através da qual um meio é tornado invisível talvez descartem a minha análise como problemática, porque revela o trabalho investido em produzir a invisibilidade, através da qual o imediatismo acontece. Isso implica que a força de uma tal análise depende de uma perspectiva alternativa que enxerga a presença das mídias onde, no quadro da ideologia semiótica em que operam, elas desapareceram.

Chegamos aqui a um paradoxo intrigante: embora durante todo este artigo eu tenha ressaltado a importância de identificar de dentro formas sensoriais específicas e ideologias semióticas que sustentam a mediação e estabelecem imediatismo, minha análise ainda requer um ponto de vista que seja externo às próprias formas sensoriais e ideologias semióticas que identifiquei como centrais a mídias que produzem engajamento. Isto faz com que surjam questões sobre nossas próprias ideologias semióticas que sustentam nosso pensamento sobre mídia enquanto acadêmicos. Eu suspeito de teorias de mídia grandiosas e universalmente aplicáveis que tentam estabelecer em termos gerais ou até mesmo universais o que é um meio e como ele funciona. Embora apresentadas como universalmente válidas, tais teorias, como eu argumentei na primeira seção deste artigo, podem ainda ter vestígios de ideologias semióticas devedoras do Protestantismo moderno. No intuito de evitar isso, nossas próprias teorias de mídia precisam de atenção crítica.

A meu ver, a antropologia tem muito a contribuir com esse projeto. $O$ fato de que a "presença" e o "desaparecimento" concomitantes das mídias parecem surgir sempre que ideologias semióticas entram em conflito - seja em um contexto de encontro entre tradições diferentes, em mudanças nas práticas de mediação que marcam um processo de transformação com relação à disponibilidade de novas tecnologias, ou como parte de análises acadêmicas - sugere que essa possibilidade de saber o que é um meio, e como ele funciona, sempre requer tanto distância quanto afinidade. Como o que um meio é só pode ser identificado a partir da adoção de uma perspectiva externa à ideologia semiótica na qual ele opera e que faz com que este, já de início, "desapareça", qualquer resposta à questão "o que é um meio" é necessariamente enganadora e reveladora ao mesmo tempo. Por essa razão, essa questão não pode ser respondida de forma direta e objetiva. O ponto é que ela pode ser abordada da forma mais produtiva ao situar-se no centro de nossas investigações o paradoxo da mediação e imediatismo em torno do qual este artigo foi desenvolvido.

Birgit Meyer é antropóloga e professora titular do Departamento de Filosofia e Ciências da Religião da Universidade de Utrecht, na Holanda. Integra a "Royal Dutch Academy of Arts and Sciences" desde 2007 e é co-editora da revista "Material Religion". 


\section{NOTAS}

1 A palavra original utilizada pela autora é "immediacy", com o sentido de "ausência de mediação" e o adjetivo "imediato". Por não haver um vocábulo em português que exprima com exatidão estes significados, optamos pela palavra "imediatismo". (N.T.)

2 Apesar de não ser usual utilizar "mídia" como plural de "meio" na língua portuguesa, optamos por esta tradução para favorecer o argumento central do artigo, que advoga uma não diferenciação entre a palavra inglesa "media" como "mídia" e "meios". (N.T.)

3 O referido texto encontra-se disponível no volume 19(1) da revista Social Anthropology, de 2011. Referência completa abaixo. (N.T.)

4 Isso me traz à mente o argumento de Niklas Luhmann (1997; ver também Krämer 2008) pelo qual em qualquer processo de mediação, o meio em si mesmo torna-se invisível. Tomando como ponto de partida o fato de que a mediação é constitutiva de toda comunicação (no sentido de que uma distância é vencida), a abordagem construtivista de Luhmann caracterizou um meio como um repertório de elementos soltos, o qual permanece invisível mas capaz de produzir uma vasta gama de formas fixas. Minha abordagem da invisibilidade da mídia difere da de Luhmann, pois eu exploro a invisibilidade em outro nível. Ao invés de tomar a invisibilidade como intrínseca à mediação em nível universal, estou interessada nos processos sociais que podem fazer um mediador "aparecer" ou "desaparecer".

5 Esse projeto de pesquisa fez-se possível graças a uma bolsa da Fundação Holandesa para Pesquisa em Ciências Sociais. Junto comigo, nove pesquisadores (cinco doutorandos: Maria José Alves de Abreu, Marleen de Witte, Francio Guadeloupe, Lotte Hoek, Martijn Oosterbaan, e quatro pós-doutorandos: Stephen Hughes, Brian Larkin, Rafael Sanchez, Mattijs van de Port), conduziram pesquisas no Oeste africano, Sul asiático, Brasil e Caribe. O projeto também facilitou curtas visitas de colegas de outros países (Meg MacLagan, Charles Hirschkind, Jeremy Stolow). Ver Meyer (2009).

6 Um novo exemplo de tal posição é a tese da "midiatização" recentemente lançada pelo sociólogo dinamarquês Stig Hjarvard (2008a, 2008b), que argumenta que, no nosso tempo, a moderna mídia de massa imprime sua própria lógica às expressões culturais. Entendido como um meta-processo que ocorre no mesmo nível que a individualização e comercialização, a midiatização referese ao poder das "mídias" (entendidas como "agentes de mudança religiosa") para enquadrar a religião nas sociedades altamente modernas, implicando o crescimento daquilo que ele chama de "religião banal". Especialmente entre os acadêmicos escandinavos da área de mídia, a teoria de Hjavard engendrou grande debate sobre o grau de agência atribuído à mídia moderna. O fato de ele próprio salientar que sua teoria pertence ao Norte Europeu secular e não pode ser aplicada globalmente, sugere que esta abordagem é de utilidade limitada para nossa pesquisa. No entanto, mesmo com relação a uma configuração Norte Europeia, desconfio da utilidade de seu quadro teórico em ajudar na compreensão e na explicação do papel das mídias na transformação da religião. Para uma discussão muito iluminadora e crítica da midiatização ver Lovheim 2011. É útil distinguir entre versões "duras" (incluindo Hjarvard) e 'maleáveis' (incluindo Hepp 2009; Lundby 2009) de miditizaação desenvolvidas nos estudos de mídia. As versões 'maleáveis' enfatizam a importância de se levar em consideração o uso social da mídia.

7 Entretanto, eu não concordo com sua crítica um tanto severa e polêmica a recentes trabalhos sobre religião e mídia como sendo fundamentados ainda nessa visão. Infelizmente, ele negligencia trabalhos em antropologia (aos quais ele se refere apenas em nota de rodapé) que criticam tais teorias de mídia. Isso, novamente, sublinha a importância de trazer insights antropológicos para debates mais amplos.

8 Alguns dos exemplos dados nesta seção são baseados na minha introdução a Formações estéticas (Meyer 2009).

9 Até agora, como Michelle Rosenthal (2007) também apontou, pesquisas em religião e mídia concentram-se principalmente na adoção de novas mídias. Entretanto, a rejeição a certas mídias e os discursos sobre isso, são também tópicos interessantes para pesquisas futuras. Isso também é um apontamento feito por Engelke (2007), o qual argumenta que a rejeição explícita de certas mídias é central para a mediação religiosa. Ver também Spyer (2001), que argumenta que a insistência do casuar em "não ser fotografado" amplifica sua aura.

10 Nesse sentido, a negociação das novas tecnologias de mídia pode ser abordada como "drama tecnológico", isto é, como tramas teatrais situadas no meio das estruturas de poder sócio-religiosas através das quais as tecnologias - em sentido amplo - são moldadas (Beck 2009). 


\section{REFERÊNCIAS BIBLIOGRÁFICAS}

ASAD, Talal. 1993. Genealogies of religion: discipline and reasons of power in Christianity and Islam. Baltimore: Johns Hopkins University Press.

BECK, Kurt. 2009. Technological dramas in the Islamic reshaping of the Sudan. Paper presented at AEGIS conference, Leipzig, July2009.

BOLTER, Jay David. and GRUSIN, Richard. 1999. Remediation: understanding new media. Cambridge, MA: The MIT Press.

CHIDESTER, David. 2008. 'Zulu dreamscapes: senses, media, and authentication in contemporary neoshamanism', Material Religion 4:135-58.

DE ABREU, Maria. José. 2005. 'Breathing into the heart of the matter: why Padre Marcelo needs no wings', Postscripts $1: 325-49$.

DE ABREU, Maria. José. 2009. In midair: breath, media, body, space. A study of the Catholic Charismatic Renewal Movement in Brazil. PhD dissertation, University of Amsterdam, February 2009.

DECERTEAU, Michel. 1984. The practice of everyday life. Berkeley: University of California Press.

DE VRIES, Hent. 2001. "In media res. Global religion, public spheres, and the task of contemporary comparative religious studies". In H. de Vries and S. Weber (eds.), Religion and media. Stanford: Stanford University Press.

DE WITTE, Marleen. 2008. Spirit media. Charismatics, traditionalists, and mediation practices in Ghana. PhD dissertation, University of Amsterdam.

DERRIDA, Jaques. 2001. "Above all, no journalists!" In H.de Vries and S. Weber (eds.). Religion and media. Stanford: Stanford University Press.

EISENLOHR, Patrick. 2006. "'As Makkah is sweet and beloved, so is Madina. Islam, devotional genres, and electronic mediationin Mauritius'". American Ethnologist 33(2):230-45.

EISENLOHR, Patrick. 2011. "What is a medium? The anthropology of media and the question of ethnic and religious pluralism". Social anthropology 19 (1): 1-5.

ENGELKE, Matthew.2007. "Text and performance in an African church: The Book, "live and direct"". American Ethnologist $31: 76-91$.

ENGELKE, Matthew. 2007. A problem of presence. Beyond scripture in an African Church. Berkeley: University of California Press.

FOX, Richard. 2009. Religion, media, and cultural studies. Religion and Culture Web Forum, Divinity School of the University of Chicago. http://divinity.uchicago.edu/martycenter/ publications/webforum/052009/Religion, \%20Media\%20and\%20 Cultural\%20Studies\%20 (MMC)-1.pdf

HEPP, Andreas. 2009. "Differentiation: mediatization and cultural change" In K. Lundby (ed.), Mediatization: concept, changes, consequences. New York: Peter Lang.

HJARVARD, Stig. 2008a. "The mediatization of society. A theory of the media as agents of social and cultural change", Nordicom Review 29:105-34.

HJARVARD, Stig. 2008b. "The mediatization of religion. A theory of the media as agents of religious change", Northern 


\section{Lights 6:9-26.}

HUGHES, Stephen. 2009. "Tamil mythological cinema and the politics of secular modernism". In Birgit Meyer (ed.) $A$ esthetic formations. Media, religion and the senses. NewYork: Palgrave.

JAMES, William.1982 [1902]. The varieties of religious experience. Harmondsworth: Penguin.

KEANE, Webb. 2007. Christian moderns. Freedom \& fetish in the mission encounter. Berkeley: University of California Press. KIRSCH, Thomas. 2008. Spirits and letters: reading, writing and charisma in African Christianity. New York: Berghahn.

KRÄMER, Sybille. 2008. Form als Vollzug oder: Was gewinnen wir mit Niklas Luhmanns Unterscheidung von Medium und Form? http://sammelpunkt.philo.at:8080/728/1/kraemer2.html (first published in1998inRechtshistorischesJournal 17:558-73).

LARKIN, Brian. 2008. Signal and noise. Media, infrastructure, and urban culture in Nigeria. Durham: Duke UniversityPress. LARKIN, Brian. 2009. "Islamic renewal, radio, and the surface of things". In B.Meyer (ed.). A esthetic formations. Media, religion and the senses. New York: Palgrave.

LATOUR, Bruno. 2005. Reassembling the social. An introduction to actor-network-theory. Oxford: Oxford UniversityPress.

LOVHEIM, Mia. 2011. "Mediatization of religion. A critical appraisal". Culture and Religion, an interdisciplinary journal 12(2): 153-166.

LUHMANN, Niklas. 1997. Die Gesel/schaftder Gesellschaft. Frankfurta. M.: Suhrkamp.

LUNDBY, Knut. 2009. "Medialogic. Looking for social interaction". In K. Lundby (ed.) Mediatization: concept, changes, consequences. NewYork: Peter Lang.

MAZZARELLA, William. 2004. "Culture, globalization, mediation". Annual Review of Anthropology 33:345-67.

MEYER, Bridget. 1998. "“Make a complete break with the past": memory and post-colonial modernity in Ghanaian pentecostalist discourse". Journal of Religion in Africa XXVII:316-49.

MEYER, Bridget. 2004. "'Praise the Lord": popular cinema and the pentecostalite style in Ghana's new public sphere". American Ethnologist 31:92-110.

MEYER, Bridget. 2005. "Religious remediations. Pentecostal views in Ghanaian video-movies". Postscripts 1: 155-81.

MEYER, Bridget. 2006a. Religious sensations. Why media, aesthetics and power matter in the study of contemporary religion. Inaugural lecture, VU University.

MEYER, Bridget. 2006b. "Religious revelation, secrecy, and the limits of visual representation". Anthropological Theory $6: 431-53$.

MEYER, Bridget. 2007. "Pentecostal and neo-liberal capitalism: faith, prosperity and vision in African Pentecostal-Charismatic churches". Journal for the Study of Religion 20:5-28.

MEYER, Bridget. (ed.) 2009. An esthetic formations. Media, religion and the senses. New York: Palgrave.

MEYER, Bridget. 2010a. "An esthetics of persuasion. Global Christianity and Pentecostalism's sensational forms". South Atlantic Quarterly 9:741-63.

MEYER, Bridget. 2010b. "“There is a spirit in that image": mass produced Jesus pictures and Protestant Pentecostal 
animation in Ghana". Comparative Studies in Society and History 52:100-30.

MEYER, Birgit. 2011. "Mediation and immediacy: sensational forms, semiotic ideologies and the question of the medium" Social Anthropology 19 (1):23-39.

MEYER, Bridget. and MOORS, Annelies. (eds.) 2006. Religion, media and the public sphere. Bloomington: Indiana UniversityPress.

MORGAN, David. 1998. Visualpiety. A history and theory of popular religious images. Los Angeles: University of California Press.

MORGAN, David. 2005. The sacred gaze. Religious visual culture in theory and practice. Los Angeles: University of California Press.

MÜLLER, Friedrich. 1893. Introduction to the science of religion; four lectures delivered at the Royal Institution in February and May 1879. London: Longmans, Green.

OOSTERBAAN, Martijin. 2009. "Purity and the Devil: Community, Media, and the Body. Pentecostal Adherents in a Favela in Rio de Janeiro". In B.Meyer (ed.) A esthetic formations. Media, religion and the senses. New York: Palgrave.

PINNEY, Christopher. 2004. 'Photos of the gods': the printed image and political struggle in India. London: Reaktion Press. ROSENTHAL, Michele. 2007. American Protestants and TV in the 1950s. Responses to a new medium. New York: Palgrave.

SÁNCHEZ, Rodrigo. 2009. "Seized by the Spirit. The mystical foundation of squatting among Pentecostals in Caracas (Venezuela) today". In B. Meyer (ed.). A esthetic formations. Media, religion and the senses. New York: Palgrave.

SCHULZ, Dorothea. 2003. "Charisma and brotherhood revisited: mass-mediated forms of spirituality in urban Mali". Journal of Religion in Africa 33:146-71.

SCHULZ, Dorothea. 2006. "Promises of (im) mediate salvation: Islam, broadcast media, and the remaking of religious experience in Mali". American Ethnologist 33:210-29.

SPYER, Patricia. 2001. "The Cassowary will not be photographed". In H. de Vries and S. Weber (eds.) Religion and media. Stanford: Stanford University Press.

STOLOW, Jeremy. 2010. Orthodox by design: Judaism, print politics, and the ArtScroll revolution. Berkeley: California University Press.

VAN DE PORT, Mattijs. 2006. "Visualizing the sacred. Video technology, "televisual style", and the religious imagination in Bahian Candomblé". American Ethnologist 33:444-61.

VAN DE PORT, Mattijs. 2009. "Don't ask questions, just observe!' Boundary politics in Bahian Candomble". In B. Meyer (ed.) A esthetic formations. Media, religion and the senses. New York: Palgrave.

VAN DER STOEP, Jan. 2009. Geloof als logo. Inaugural lecture. Christelijke Hogeschool Ede.

VERBEEK, P.P. 2005. What things do. Philosophical reflections on technology, agency, and design. University Park: Penn State University Press.

WEBER, Max. 1970 [1948]. "Religious rejections of the world and their directions". In Max Weber Essays in sociology. With an introduction by H. H. Gerth and C. Wright Mills. London: Routledge \& Kegan Paul. 


\section{Mediação e Imediatismo: formas sensoriais, ideologias semióticas e a questão do meio}

\section{RESUMO}

Tomando como ponto de partida o paradoxo de que imediatismo não é anterior, mas antes um produto da mediação, esse artigo argumenta que a negociação de tecnologias mediáticas recentes é um elemento-chave para a transformação da religião. Invocada para autorizar a experiência de poderes espirituais como imediatos e reais, a mídia tende a "desaparecer" ou se tornar "hiper-aparente" no ato da mediação. Argumento que entender a mídia como intrínseca à religião exige uma crítica fundamental das abordagens, tanto da religião quanto da mídia, que propõem uma oposição entre mídia e imediatismo.

PALAVRAS-CHAVE: mídia; religião; Pentecostalismo; sentidos; Ghana

\section{Mediation and immediacy: sensational forms, semiotic ideologies and the question of the medium}

\section{ABSTRACT}

Taking as a starting point the paradox that immediacy is not prior to, but rather a product of mediation, this article argues that the negotiation of newly available media technologies is key to the transformation of religion. Invoked to authorise sensations of spiritual powers as immediate and real, media are prone to 'disappear' or become 'hyperapparent' in the act of mediation. I argue that a view of media as intrinsic to religion requires a fundamental critique of approaches of both religion and media that posit an opposition between media and immediacy.

KEYWORDS: media; religion; Pentecostalism; senses; Ghana

\section{TRADUZIDO DE}

Meyer, Brigit. 2011. "Mediation and immediacy: sensational forms, semiotic ideologies and the question of the medium". Social Anthropology/Anthropologie Sociale 9(1): 23-39. Doi:10.1111/j.1469-8676.2010.00137.x

Tradução: Mayra Sousa Resende e Willian Perpétuo Busch

Revisão: João Frederico Rickli

Recebido: 02/10/2015

Aprovação: 22/02/2017 